then dropping to less than $10 \%$ between 100 and 140 days. In planters with the second addition of the alternate host, there was a marked increase in bioassay insects infected with the nematode from 160 days onward. Planters without the alternate host remained at a low level (less than 15\% bioassay insects infected) until 240 days when the percentage of infected bioassay insects increased to $50 \%$.

Both S. feltiae and H. bacteriophora treatments with the alternate host had a higher nematode population than treatments without the alternate host, suggesting that the nematodes used them to reproduce. Yet, the long persistence of $S$. feltiae and $H$. bacteriophora in treatments without the alternate host suggested that they, too, were reproducing in BVW larvae and pupae. Indeed, upon destructive sampling of all planters at the end of the experiment, BVW larvae and pupae were recovered from all treatments (fig. 3). Control planters had significantly higher BVW populations than did the nematode treatments, but no significant differences were observed among nematode treatments with or without the alternate host.

\section{Conclusions}

Our experiment demonstrated that $S$. feltiae and $H$. bacteriophora can reproduce when suitable hosts are present in potted soil. More significantly, the nematodes reduced BVW infestations to a very low level. The periodic addition of alternate hosts to boost nematode populations is not practical for these commercial buildings where large numbers of planters are maintained for several years. Rather, a periodic check for BVW as previously suggested (California Agriculture, January-February 1985) may be a more prudent method for managing this insect. If BVW are found, nematodes can be applied and then augmented, as needed, to bolster the existing nematode population in suppressing this pest. Because they are safe to use and their potential for long-term control is evident, insect-parasitic nematodes are preferable to chemical control in managing BVW in buildings with containerized landscapes.

T. M. Burlando is Staff Research Associate, $H$. K. Kaya is Professor, and P. Timper was Graduate Student, Department of Nematology, UC Davis, and is now a research scientist with the USDA, Cornell University, Ithaca, New York.

The authors thank Mark Buttner, grounds supervisor of the San Francisco commercial building complex where the research was conducted; Al Hom of biosys, Palo Alto, California, and Bioenterprises of Australia for their assistance, as well as the Elvenia J. Slosson Endowment Fund for its financial support.

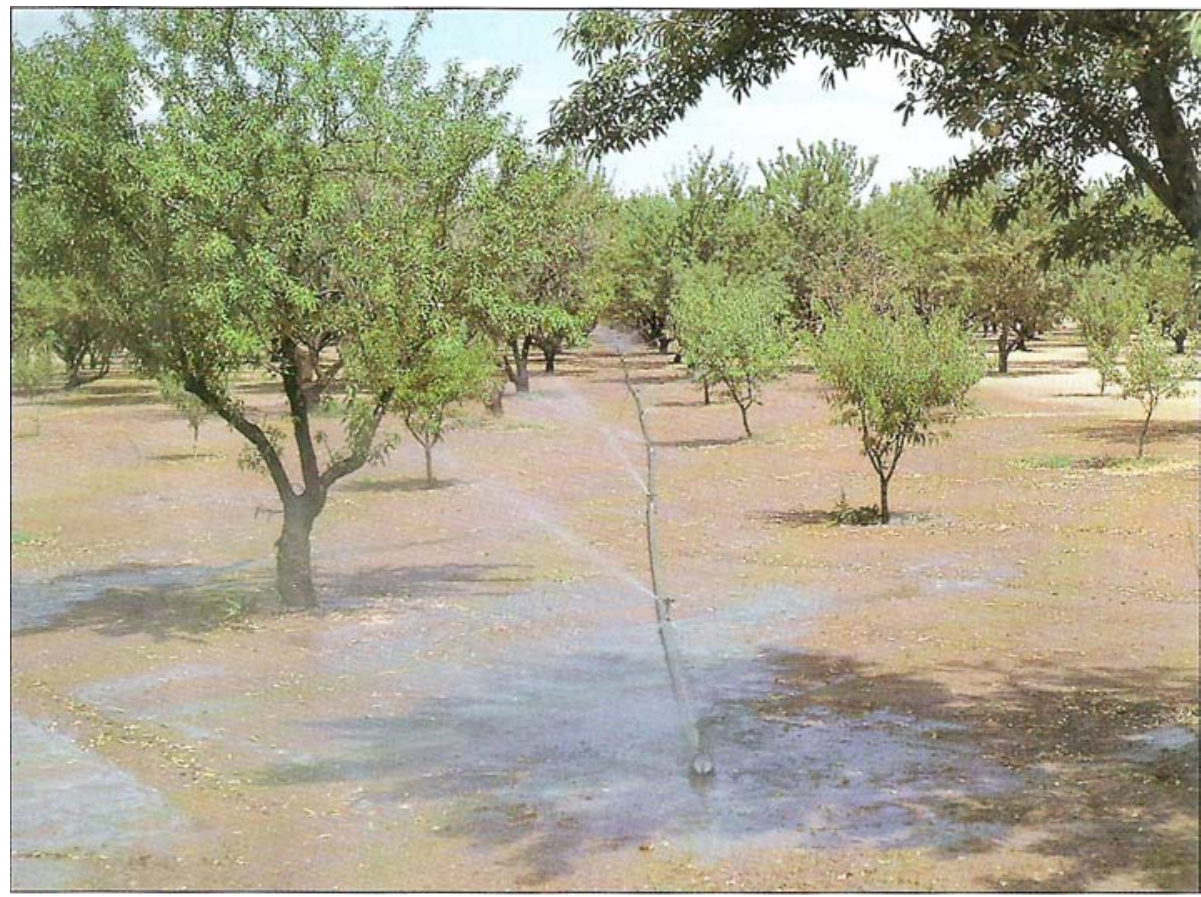

Almond orchard being irrigated with sprinklers.

\title{
Uniformity in pressurized irrigation systems depends on design, installation
}

\author{
Gordon E. Little $\quad \square$ David J. Hills $\square$ Blaine R. Hanson
}

Of 258 irrigation systems evaluated
by mobile field laboratories in five Southern California resource conservation districts, average uniformity in distribution of water was relatively low. Generally, farms larger than 100 acres had systems with higher uniformity in distribution. Age of a system did not necessarily account for poor distribution. What did account for it was variation in pressures due to inadequate system design or to installation of incorrect hardware.

To encourage conservation of agricultural water, the Mobile Field Lab Program, sponsored by the California Department of Water Resources and local resource conservation districts (RCDs), has evaluated 1,200 farm irrigation systems since 1985.
Of this total, 258 reports pertain to pressurized irrigation systems for orchards 189 micro-spray, 56 drip and 13 sprinkler. The orchards, deciduous, citrus and avocado, are all located in Kern, Ventura, Riverside and San Diego counties. Farms vary in size from a few acres up to 400 and in age between 1 year and 30 .

Field teams collected data on hardware size, type and location, and on water pressures and discharge flow rates at strategic points in the system. Information on chemical injection, filtration and lateral flushing was also obtained. Teams evaluated single irrigation events and the irrigation system's water distribution uniformity. Using these data and information gained from interviews with growers, the teams also estimated each farm's annual irrigation efficiency.

\section{Background}

Primary emphasis was on each system's distribution uniformity (DU), a 


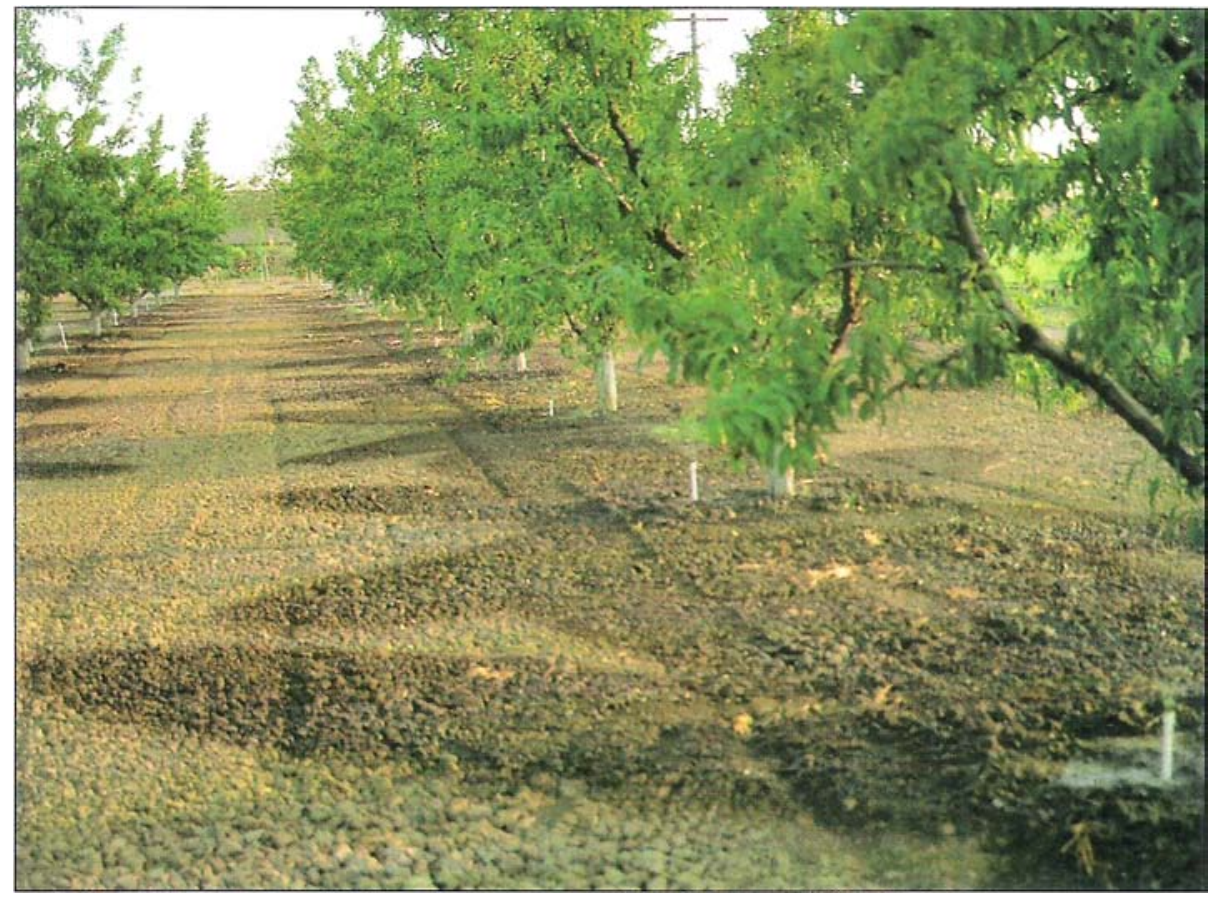

Micro-spray irrigation of a young peach orchard.

measure of the uniformity of irrigation water application over an orchard. It is defined as the ratio of the minimum depth of water infiltrated to the average depth of water infiltrated throughout an orchard. Minimum depth infiltrated is taken as the average in the lowest $25 \%$ of the orchard. Normal irrigation practice attempts to deliver the minimum required amount of water to this lowest $25 \%$. An unfavorable effect of this practice is that the rest of the orchard is overirrigated, costing more money for excess water and more energy for application.

Greater extremes occur in the maximum and minimum application depths for lower DU values. A high DU value, then, implies greater uniformity of irrigation water application and less use of excess water. The U.S. Soil Conservation Service general criteria for DU values for systems in operation one or more seasons are: $90 \%$ or greater, excellent; between 80 and $89 \%$, good; 70 to $79 \%$, fair; and $69 \%$ or less, poor.

Application efficiency $(\mathrm{Ea})$ is the ratio of water beneficially used to the total amount of water applied. Therefore, all water applied in excess of the minimum annual irrigation requirement is not beneficially used.

The DU can be considered a measure of the installed irrigation system's efficiency. The Ea is a measure of system management efficiency as well as irrigation system efficiency. Therefore, while a high DU does not necessarily equal a high $\mathrm{Ea}$, a high Ea is not possible without a high DU.

\section{Differences in RCDs}

Data from irrigation reports and discussions with mobile team leaders indicated major differences among the five RCDs in terrain, farm sizes and cost of water (table 1). The Pond-Shafter-Wasco and Coachella areas are composed primarily of flat terrain; the Ventura, Mission, and Riverside-Corona areas include hilly terrain.

Table 2 summarizes data for all five areas and for each type of irrigation system. Included are the number of systems, acreage, average DU, area-weighted DU, and overall averages and totals for the combined data. (When calculating the areaweighted DU for a region, more significance was placed on a larger farm than a smaller one.)

The 258 farms represented approximately 10,000 acres with an overall aver- age area-weighted DU of 74\%. "Poor" with the lowest average DU value $(66 \%)$ is Ventura RCD. "Fair" are Mission RCD (71\%), Coachella RCD (75\%) and Riverside-Corona RCD (75\%). "Good" is PondShafter-Wasco RCD (83\%). No RCD studied is "excellent" (DU values above 90\%); values exceeded this level, however, on individual farms.

Less than $3 \%$ of the Ventura systems had a DU greater than $90 \%$ (fig. 1). About $18 \%$ were rated between 80 and $90 \%$; nearly $54 \%$ had a DU less than $70 \%$. In Riverside (fig. 2), $12 \%$ had DUs greater than $90 \% ; 52 \%$ were between 80 and $90 \%$, and only $15 \%$ were less than $70 \%$. About $20 \%$ of the DUs in Coachella (fig. 3) were greater than $90 \%$; about $32 \%$ were between 80 and $90 \%$, and $26 \%$ of the values were less than $70 \%$. Coachella's high values may be attributed to relatively flat terrain and to the fact that most systems tested were less than 5 years old.

Distribution uniformities. Comparing the three systems - micro-spray, drip and sprinkler - is difficult because their installation and operation differ greatly. An approximate comparison can be made by averaging the uniformity data. As indicated in table 2, average area-weighted DU values for drip and micro-spray systems are $75 \%$ and $72 \%$, respectively. These values are calculated from 56 drip systems and 189 micro-spray systems, and for a variety of topographical conditions. The 13 sprinkler systems, on relatively nonundulating terrain, have an average area-weighted DU value of $82 \%$. Because of their many differences, however, none of the systems (micro-spray, drip or sprinkler) can be meaningfully compared.

Pressure variations. Data on the micro-irrigation systems indicate that the largest single cause of low DU values is

\begin{tabular}{|c|c|c|c|}
\hline $\mathrm{RCD}$ & County & Water district & Price \\
\hline & & & S/ac-ft \\
\hline Ventura & Ventura & $\begin{array}{l}\text { Casittas, } \\
\text { Metropolitan }\end{array}$ & $\begin{array}{c}91 \\
200-350\end{array}$ \\
\hline $\begin{array}{l}\text { Pond-Shafter- } \\
\text { Wasco }\end{array}$ & Kern & $\begin{array}{c}\text { USBR, } \\
\text { State Project }\end{array}$ & $\begin{array}{c}65 \\
200\end{array}$ \\
\hline Riverside-Corona & Riverside (west) & Metropolitan & $350-500$ \\
\hline Mission & San Diego & 5 districts & $394-617^{*}$ \\
\hline Coachella & Riverside (central) & USBR & 15 \\
\hline
\end{tabular}




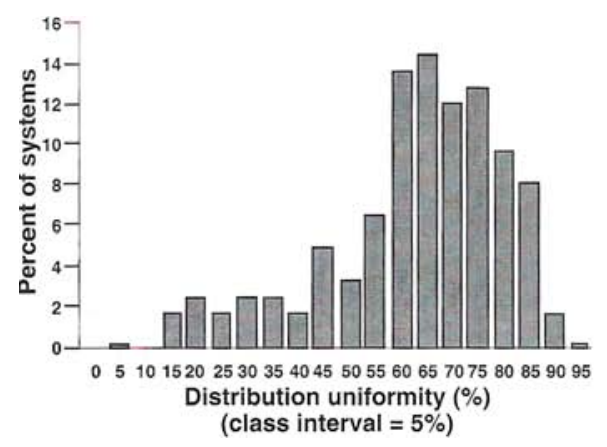

Fig. 1. Frequency distribution of distribution uniformity (DU) values for $125 \mathrm{drip} / \mathrm{mi}$ cro-spray systems in Ventura Resource Conservation District (RCD).

pressure variation within manifolds and laterals. Pressure variations account for $52 \%$ of nonuniformity. Accounting for the remaining $48 \%$ are manufacturing variations, clogging, emitter spacing variations and emitter discharge after system shutdown. Excessive pressure variations are caused by undulating terrain and by excessive lateral lengths. Variations in pressure can be corrected by using larger-diameter manifolds and laterals, using shorter manifolds and laterals, installing pressure regulators at appropriate locations and using pressure-compensating emitters.

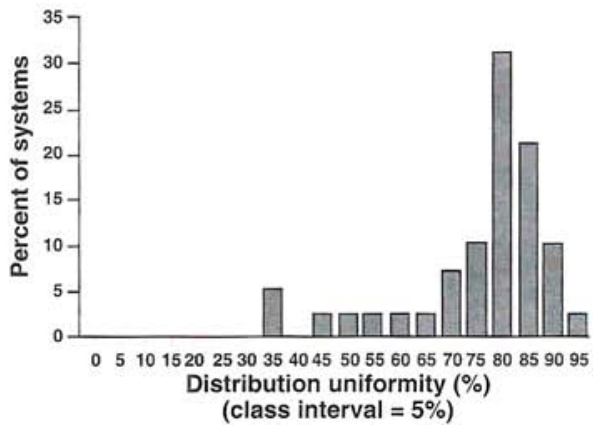

Fig. 2. Frequency distribution of DU values for 42 drip/micro-spray systems in Riverside-Corona RCD.

Filtration and lateral flushing. Preventing emitter plugging, a major contributor to low DU, requires maintaining clean emitters, including water filtration, lateral flushing, and chemical water treatment. All systems utilized filtration units according to recommendations of the emitter manufacturer. Lateral flushing, however, was not practiced for most systems. On $69 \%$ of the farms, irrigation systems were never flushed. Average DU values for systems with at least annual lateral flushing was $12 \%$ higher than for those systems with unflushed laterals. Flushing minimizes buildup of clay and silt sedi-

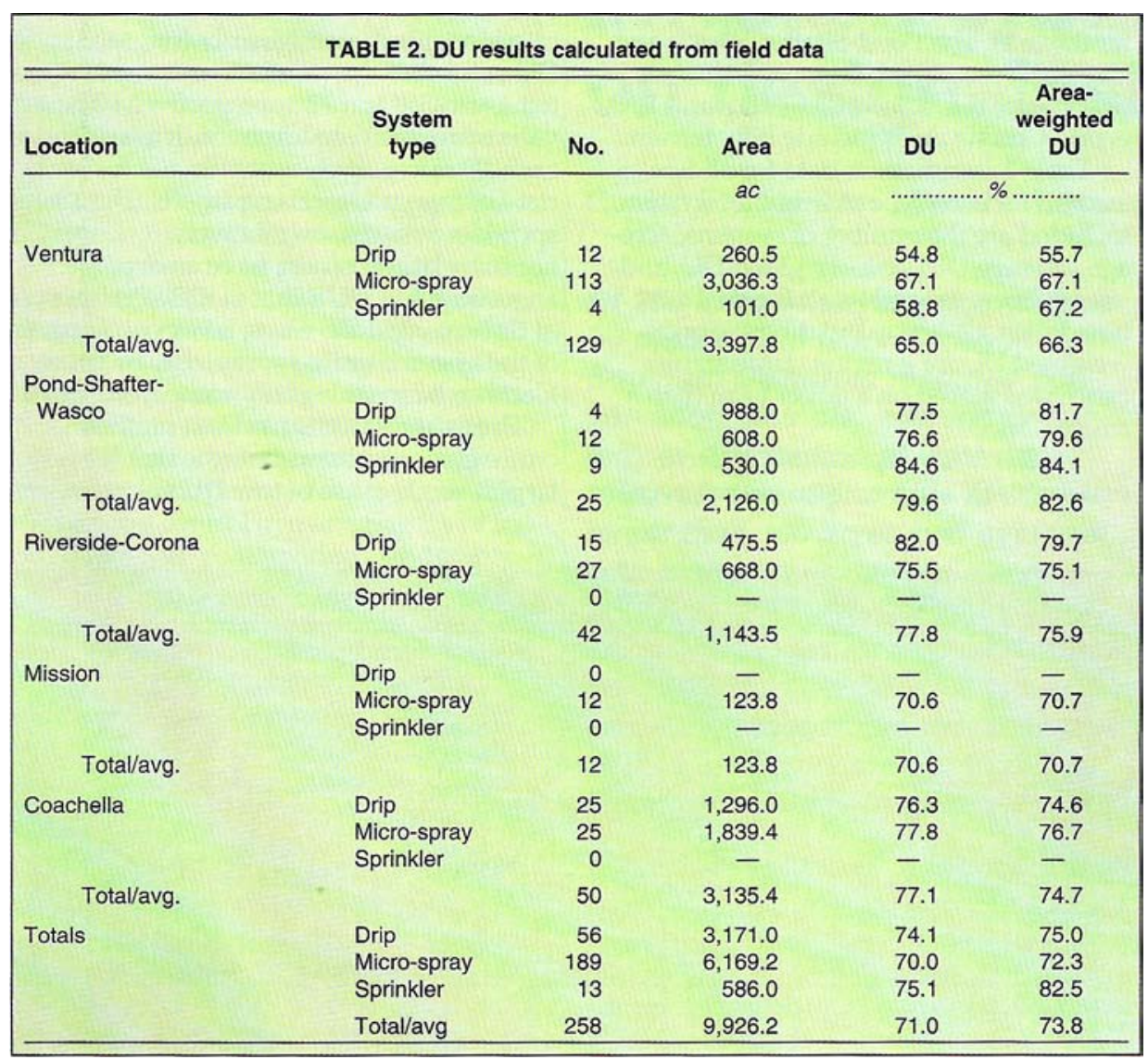

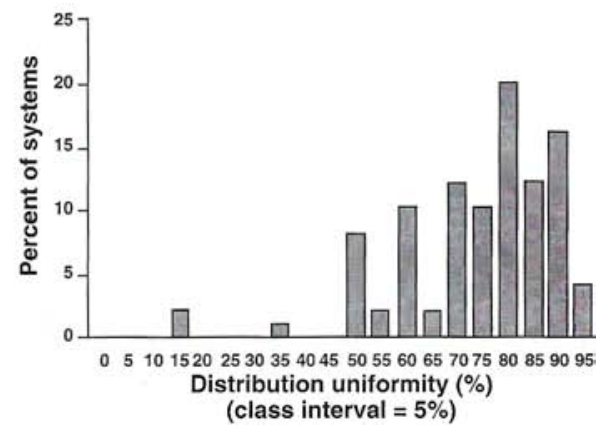

Fig. 3. Frequency distribution of DU values for $50 \mathrm{drip} / \mathrm{micro}$-spray systems in Coachella RCD.

ments, both of which pass through typical screen filters.

Chemical injection. In all, $66 \%$ of the farms used chemical injection for fertilizer application and for chlorine water treatment. DU values for these farms were $7 \%$ higher than for the DUs of farms without chemical injection systems. Of the farms with injection systems, uniform injection was not possible for $69 \%$ of them because of inadequate hardware. Chlorine injection to control bacterial and algal growth was never applied on $70 \%$ of the farms. Average DU values for systems with at least annual chlorine injection (and including weekly or monthly applications) was $12 \%$ higher than for those systems which never injected chlorine. About $44 \%$ of the systems injected chemicals downstream from the filters. However, average DU of systems with injection downstream of the

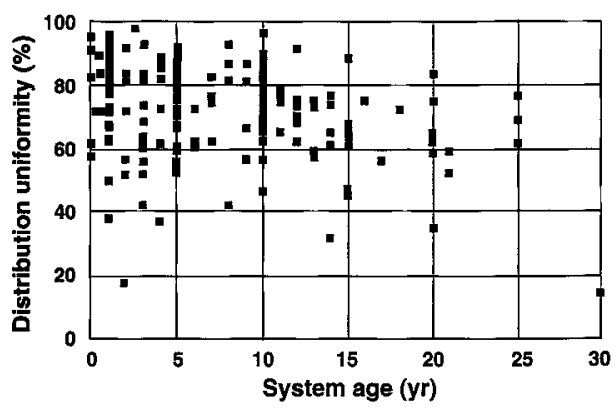

Fig. 4. Effects of irrigation system age on DU.

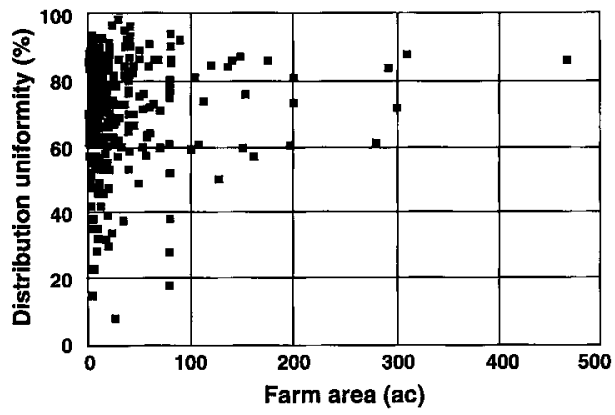

Fig. 5. Effects of orchard size on DU. 
filter was about $75 \%$; average DU of those injecting upstream of the filter was $70 \%$.

Flow meters. Flow meters are necessary for good management of irrigation water. However, about $26 \%$ of the systems evaluated do not have a flow meter. This percentage varies from $7 \%$ for the Riverside systems to $44 \%$ in Coachella, which also has the lowest priced water (see table 1).

DU variations, system age. The combined DU values versus system age for all five RCD areas are plotted in figure 4. Data indicate that a large number of new and relatively new systems (5 years old or less) have very low DU values. Because these systems are young, it can be concluded that they do not suffer from operational problems (emitter clogging or use of a mixture of different emitters). Rather, low DU values primarily result from bad system design initially. This conclusion suggests the need for more adequate training, even licensing, of system designers. Visual inspection of figure 4 data indicates that there is little correlation between DU and system age.

DU variations, farm size. Combined DU values versus farm size for the five RCDs are plotted in figure 5. These data indicate that as farm size increases, very poor DU values (that is, below $60 \%$ ) decline; none are evident on farms larger than 200 acres. This fact may indicate that irrigation systems on larger farms are better designed, operated and maintained.

\section{Conservation potential}

Improving DU reduces the amount of water applied and therefore conserves energy. The following procedure assumes that the minimum annual irrigation requirement $\left(\mathrm{Y}_{\mathrm{m}}\right)$ is being applied to the low quarter of the farm area, as per good irrigation practice, and that it is desired to improve the system distribution uniformity from a present value of $\mathrm{DU}_{1}$ to a higher value of $\mathrm{DU}_{2}$ (that is, $90 \%$ ).

The depth of overapplied water depends on the existing DU and the total annual applied water. Figure 6 presents a plot of existing DU value versus depth of overapplied water for an improvement in DU value to $90 \%$ and for a range of $Y_{m}$ values from 40 to 80 inches.

Cost of water for a range of overapplication depths is presented in figure 7 at water prices from $\$ 100$ to $\$ 500$ per acre-foot (ac- $\mathrm{ft}$ ). The cost of energy for the same range of overapplication depths is presented in figures 8 and 9 for energy rates of 10 and 15 cents per kilowatt-hour $(\mathrm{kWh})$, respectively. Each graph assumes a pumping efficiency of $80 \%$ and covers a range of pump heads from 50 to 250 feet.

Example. A mature San Joaquin Valley almond orchard with a sprinkler system has a DU value of $75 \%$. Annual irrigation

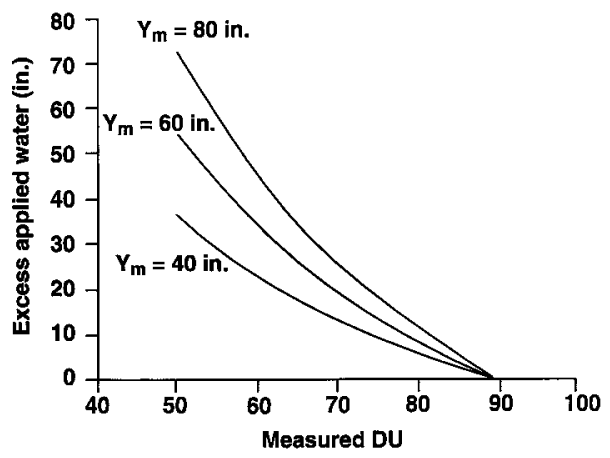

Fig. 6. Depth of water applied in excess of minimum annual irrigation requirement, $\mathrm{Y}_{\mathrm{m}}$, due to DU values less than $90 \%$.

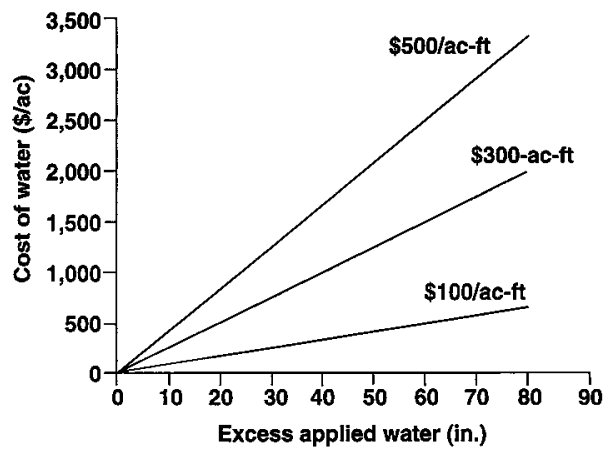

Fig. 7. Additional irrigation cost for excess water due to low uniformity.

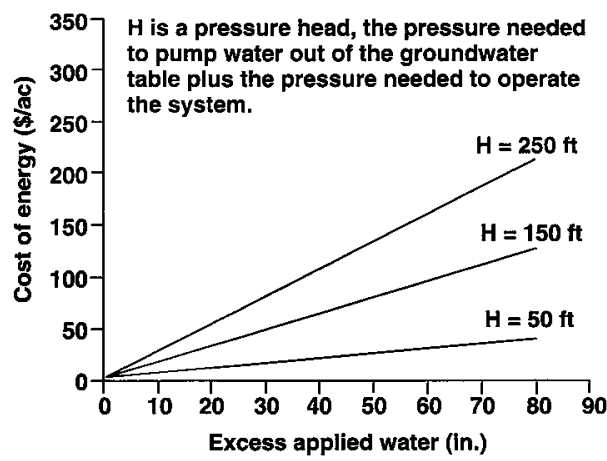

Fig. 8. Additional irrigation cost for excess energy due to low uniformity (at 10 cents per $k$ Wh).

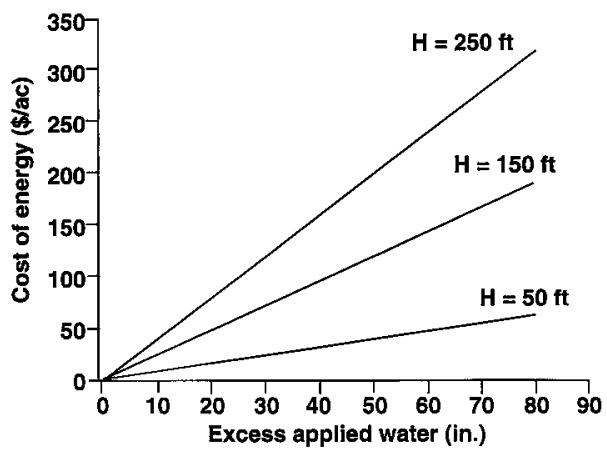

Fig. 9. Additional irrigation cost for excess energy due to low uniformity (at 15 cents per $\mathbf{k W h}$ ). minimum requirement is 50 inches, water cost is $\$ 100$ per ac- $\mathrm{ft}$, energy cost is 10 cents per $\mathrm{kWh}$, and system operating pressure is 60 pounds per square inch (psi). Water is delivered to the farm in an open canal. What would be the annual cost savings if the DU were increased to $90 \%$ ?

(1) From figure 6, depth of excess-applied water is equal to 12 inches.

(2) From figure 7, cost of excess-applied water is equal to about $\$ 100$ per acre.

(3) System pressure of 60 psi times 2.3 equals 138 feet of pressure head. From figure 8 , cost of energy is equal to about $\$ 25$ per acre.

(4) Total annual cost of the excess-applied water is therefore equal to $\$ 100$ per acre for water plus $\$ 25$ per acre for energy, or about $\$ 125$ per acre.

\section{Conclusions}

Improvement of DU values and management of the irrigation system so that the correct amount of water is applied can lead to substantial savings in cost and the volume of water applied. Whether these improvements are implemented by the grower depends on government regulations, costs of the improvement, costs of the water and energy, effect on crop yields, and related factors, such as agricultural sustainability and environmental health and safety.

The following conclusions can be stated:

(1) Micro-irrigation has potential for highly efficient water application; however, many farm systems tested had relatively low values because of incorrect design or poor maintenance.

(2) Average DU for all 258 tested systems is a "fair" $74 \%$.

(3) No correlation is observed between system age and DU values. Although

management may be a factor, this lack of correlation probably indicates that many systems were inadequately designed initially.

(4) Some correlation exists between farm sizes and DU values. For farm sizes below 100 acres, a broad range of DU values is evident; for larger sizes, there are no very poor DU values.

G. E. Little is Senior Engineer, California Department of Water Resources, Sacramento; $D$. J. Hills is Professor and Chair, Department of Biological and Agricultural Engineering, UC Davis; and B. R. Hanson is Irrigation and Drainage Extension Specialist, UC Davis.

Funding for this project was partially provided by the Committee on the Relation of Energy to Agriculture (CREA). The authors gratefully acknowledge the help of the Office of Water Conservation, California Department of Water Resources, in providing the field evaluations used in this study. 